\title{
Magnetocaloric Properties of $\mathrm{Mn}_{1.1} \mathrm{Fe}_{0.9} \mathrm{P}_{0.5} \mathrm{As}_{0.5-x} \mathrm{Ge}_{x}$ $(0 \leq x \leq 0.1)$ Compounds
}

\author{
Patryk Wlodarczyk ${ }^{1, *}$, Lukasz Hawelek ${ }^{1}$, Maciej Kowalczyk ${ }^{2}$, Malgorzata Kaminska ${ }^{1}$, \\ Marcin Polak ${ }^{1}$, Andrzej Hudecki ${ }^{1}$ and Aleksandra Kolano-Burian ${ }^{1}$ \\ 1 Institute of Non-Ferrous Metals, ul. Sowinskiego 5, 44-100 Gliwice, Poland; lukaszh@imn.gliwice.pl (L.H.); \\ malgorzata.kaminska@imn.gliwice.pl (M.K.); marcin.polak@imn.gliwice.pl (M.P.); \\ andrzej.hudecki@gmail.com (A.H.); olak@imn.gliwice.pl (A.K.-B.) \\ 2 Faculty of Materials Science and Engineering, Warsaw University of Technology, ul. Woloska 141, \\ 02-507 Warsaw, Poland; mmkowalczyk@gmail.com \\ * Correspondence: patrykw@imn.gliwice.pl
}

Academic Editor: Christof Schneider

Received: 5 April 2017; Accepted: 10 May 2017; Published: 13 May 2017

\begin{abstract}
Intermetallic compounds with the overall formula $\mathrm{Mn}_{1.1} \mathrm{Fe}_{0.9} \mathrm{P}_{0.5} \mathrm{As}_{0.5-x} \mathrm{Ge}_{x}$ ( $x$ varies from 0 to 0.1 ) were investigated in order to study their magnetocaloric effect by monitoring the adiabatic temperature change, magnetic entropy change and their relation to structural parameters. It was found that the maximum of magnetocaloric effect was achieved for $x=0.02$. Adiabatic temperature change for consolidated powder was equal to $2.75 \mathrm{~K}$ for the magnetic field change $\Delta \mathrm{B}=1.7 \mathrm{~T}$ for the sample with $x=0.02$. For the pure non-doped sample, this parameter is much lower: $\Delta \mathrm{T}_{\mathrm{ad}}=1.7 \mathrm{~K} @ \Delta \mathrm{B}=1.7 \mathrm{~T}$. This result was correlated with the change of structural parameters such as lattice constants and the unit cell volume.
\end{abstract}

Keywords: magnetocaloric effect; adiabatic temperature change; crystal structure; intermetallic compound

\section{Introduction}

Compounds exhibiting large magnetocaloric effect in the vicinity of room temperature have recently drawn much attention due to the possibility of their application in magnetic cooling devices. Among the different types of intermetallic compounds, two groups exhibiting magnetoelastic ferro to paramagnetic state transition are the most prospective. The first one, an $\mathrm{La}(\mathrm{Fe}, \mathrm{Si})_{13}$ group of compounds, is being optimized by introducing cobalt and manganese into the composition and by performing hydrogenation [1-6]. All of these procedures are aimed toward shifting the Curie point to the desired room temperature. The second group, which is the subject of this study, constitutes a big family of $\mathrm{Fe}_{2} \mathrm{P}$-based compounds. The three main groups are: $(\mathrm{Mn}, \mathrm{Fe})_{2}(\mathrm{P}, \mathrm{As})$, $(\mathrm{MnFe})_{2}(\mathrm{P}, \mathrm{Ge})$ and $(\mathrm{MnFe})_{2}(\mathrm{P}, \mathrm{Si})$ compounds. Our study is focused on the $(\mathrm{Mn}, \mathrm{Fe})_{2}(\mathrm{P}, \mathrm{As})$ group, which is known to exhibit the best magnetocaloric properties (highest adiabatic temperature change) [7-13]. Most of the studies have concentrated on intermetallic compounds based on four elements. In our study, we will investigate five-element intermetallic compounds with the overall formula: $\mathrm{MnFeP}_{0.5} \mathrm{As}_{0.5-x} \mathrm{Ge}_{x}$. In 2005, Tegus et al. published results of a germanium substitution for arsenic for a $\mathrm{Mn}_{1.1} \mathrm{Fe}_{0.9} \mathrm{P}_{0.7} \mathrm{As}_{0.3-x} \mathrm{Ge}_{x}$ series [14]. In the studied samples, a composition with the germanium amount $x=0.1$ was found to have the highest magnetic entropy change in the high magnetic field $B=3 \mathrm{~T}$. Under a moderate magnetic field of $\mathrm{B}=1 \mathrm{~T}$, the highest magnetic entropy change was found for the composition with $x=0.15$ (approximately $-\Delta \mathrm{S}_{\mathrm{M}}=11 \mathrm{~J} \cdot \mathrm{kg}^{-1} \cdot \mathrm{K}^{-1}$ ), however, adiabatic temperature change was not evaluated during this study. The Curie point for the composition with $x=0.10$ was obtained as $\mathrm{T}_{C}=270 \mathrm{~K}$, while for $x=0.15$ it was $\mathrm{T}_{C}=290 \mathrm{~K}$. 
In our recent study, it was found that silicon as a fifth element (substituted for arsenic) may increase magnetic entropy change as well as adiabatic temperature change in $\mathrm{Fe}_{2} \mathrm{P}$-type compounds. It was also found that the maximum adiabatic temperature change in silicon-doped $\mathrm{MnFeP}_{0.35} \mathrm{As}_{0.65}$ compounds can be correlated with the maximum crystal unit cell volume [15].

The main aim of this work is to study the impact of doping the known composition $\mathrm{Mn}_{1.1} \mathrm{Fe}_{0.9} \mathrm{P}_{0.5} \mathrm{As}_{0.5}$ by germanium $\mathrm{Ge}$ on structural and magnetocaloric parameters (adiabatic temperature change $\Delta \mathrm{T}_{\mathrm{ad}}$ and magnetic entropy change $\Delta \mathrm{S}_{\mathrm{M}}$ ). The second aim is related to finding correlations between structural changes and magnetocaloric properties. In this case, contrary to the silicon atom (atomic radius $r=110 \mathrm{pm}$ ), germanium has a higher atomic radius than arsenic (125 versus $115 \mathrm{pm}$ ), which should cause unit cell enlargement. Newly synthetized compounds will be studied by means of calorimetry, X-ray diffraction, microanalysis, magnetometry and magnetocalorimetry. Moreover, magnetic entropy change $\left(\Delta S_{M}\right)$ under a moderate magnetic field $(\mathrm{B}=1 \mathrm{~T})$ will be calculated from magnetometric measurements.

\section{Materials and Method}

Approximately $15 \mathrm{~g}$ samples were prepared by initial high energy ball milling the stoichiometric mixture of elemental powder Fe (3 N), red phosphorous $\mathrm{P}(2 \mathrm{~N} 5)$, elemental shots Mn (4N), Ge (5N) and $\mathrm{FeAs}_{2}$ (2N5) compounds under an argon atmosphere. Powders were then pressed in order to form pellets. Pellets were sintered for $5 \mathrm{~h}$ at $1273 \mathrm{~K}$ and homogenized for the next $10 \mathrm{~h}$ at $923 \mathrm{~K}$ under a vacuum $5 \times 10^{-5}$ mbar (wire vacuum furnace, Czylok, Poland). Thereafter, samples were slowly cooled down with the furnace to room temperature.

The phase purity and the crystal structures were determined by powder X-ray diffraction (XRD) using $\mathrm{Cu}_{\alpha}$ radiation (MiniFlex, Rigaku, Japan). The Rietveld refinement analysis of the X-ray diffraction data were performed using FullProf Suite Program 3.00 [16]. The microstructure observations and chemical composition evaluation was done by JCXA 733 (JEOL, Japan) equipped with energy dispersive (EDS) and wavelength dispersive (WDS) microanalyzers. The direct adiabatic temperature changes $\Delta \mathrm{T}_{\mathrm{ad}}(\mathrm{T}, \mathrm{B})$ were obtained with an adiabatic magnetocalorimeter (AMT\&C Group, Russia) in a temperature range of $170-350 \mathrm{~K}$ under magnetic fields up to $1.7 \mathrm{~T}$. The external magnetic field was changed in a cycle of $0 \mathrm{~T}-1.7 \mathrm{~T}-0 \mathrm{~T}$ with a rate of $2 \mathrm{~T} / \mathrm{s}$, during $\Delta \mathrm{T}_{\mathrm{ad}}$ measurements. $\Delta \mathrm{T}_{\text {ad }}$ measurements were performed on the samples that were initially milled, mixed and consolidated with $5 \%$ of polyvinylidene fluoride (PVDF) powder by heating to $573 \mathrm{~K}$ and pressing. Tablets prepared by this method are resistant to the large magnetovolume effect during the measurements, but exhibit lower maximum $\Delta \mathrm{T}_{\mathrm{ad}}$ than the bulk samples. Differential scanning calorimetry (DSC) studies were performed with use of a Pegasus 404c thermal analyzer (Netzsch, Germany). Samples with a mass of approximately $30 \mathrm{mg}$ were heated with at the rate of $10 \mathrm{~K} / \mathrm{min}$ under a helium atmosphere a gas flow equal to $50 \mathrm{~mL} / \mathrm{min}$.

Magnetic measurements were performed using a Physical Property Measurement System (PPMS-7, Quantum Design, Inc., San Diego, CA, USA). Compounds exhibiting first order magnetic transition were being studied. Therefore, it was advisable to perform isofield measurements or to use the so called "loop process" during isothermal measurements in order to avoid artifacts ("spikes") at the calculations of magnetic entropy change stage. In this work, isofield measurements were carried out. Magnetization curves $\mathrm{M}=f(\mathrm{~T})$, measured for different values of magnetic field induction were further interpolated to obtain the same temperature steps for every value of magnetic field induction, enabling use of the Maxwell relations-based formula for magnetic entropy change calculations [17]:

$$
\Delta S=\sum_{i} \frac{M\left(T+\frac{\Delta T}{2}, B_{i}\right)-M\left(T-\frac{\Delta T}{2}, B_{i}\right)}{\Delta T} \cdot \Delta B_{i} .
$$

The magnetization was measured in a temperature range of $250-400 \mathrm{~K}$ under magnetic fields up to $1 \mathrm{~T}$. 


\section{Results and Discussion}

Synthetized compounds were investigated by different experimental methods. The structure of polycrystalline samples was evaluated by XRD. In Figure 1 (left), one can see the diffraction patterns of all of the studied samples. It can be easily seen that all samples consisted of two phases i.e., major hexagonal $\mathrm{Fe}_{2}$ P-type phase (space group number: 189, Hermann-Mauguin symbol: $\mathrm{P}-62 \mathrm{~m}$ ) and MnO impurity (space group number: 225, Hermann-Mauguin symbol: $\mathrm{F} \mathrm{m}-3 \mathrm{~m}$ ). By analyzing the diffraction patterns from 50 to 55 degrees in the $2 \theta$ range, it is easily seen that position of the (002) diffraction peak shifts into the smaller value in the 2Theta scale into the position of the (211) peak. Thus, in a high temperature phase (paramagnetic) three maxima are visible instead of two. For paramagnetic samples, the (002) peak shifts into the higher value of the 2Theta value and the so-called "diffraction triplet" from the (300), (211) and (002) peaks is visible in the 50-55 degrees region. Therefore, the sample with composition $\mathrm{MnFeP}_{0.5} \mathrm{As}_{0.48} \mathrm{Ge}_{0.02}$ is ferromagnetic (FM) at room temperature, while $\mathrm{MnFeP}_{0.5} \mathrm{As}_{0.46} \mathrm{Ge}_{0.04}$ is paramagnetic (PM). Both compounds exhibit FM-PM transition near room temperature. The weight fractions of the phases, lattice parameters, unit-cell volume and $c / a$ ratio for the $\mathrm{Fe}_{2} \mathrm{P}$-type phase were then refined using the Rietveld method, and are presented in Table 1. The selected Rietveld refinement pattern for the sample of $\mathrm{Mn}_{1.1} \mathrm{Fe}_{0.9} \mathrm{P}_{0.5} \mathrm{As}_{0.4} \mathrm{Ge}_{0.1}$ is shown in Figure 1 (right). The purity of the synthetized compounds was checked by performing microstructural analysis. In Figure 2, SEM images of two samples with germanium amounts of $x=0.02$ and $x=0.08$ have been presented. The system with the amount of germanium $x=0.02$ is ferromagnetic at room temperature, while the sample with $x=0.08$ is paramagnetic. The average as well as phase composition was evaluated by means of EDS and WDS analysis. It was found that the paramagnetic sample is more porous than the ferromagnetic sample. Performed microanalysis showed that the manganese oxide $\mathrm{MnO}$ can be found mainly in the pores of the presented structure.
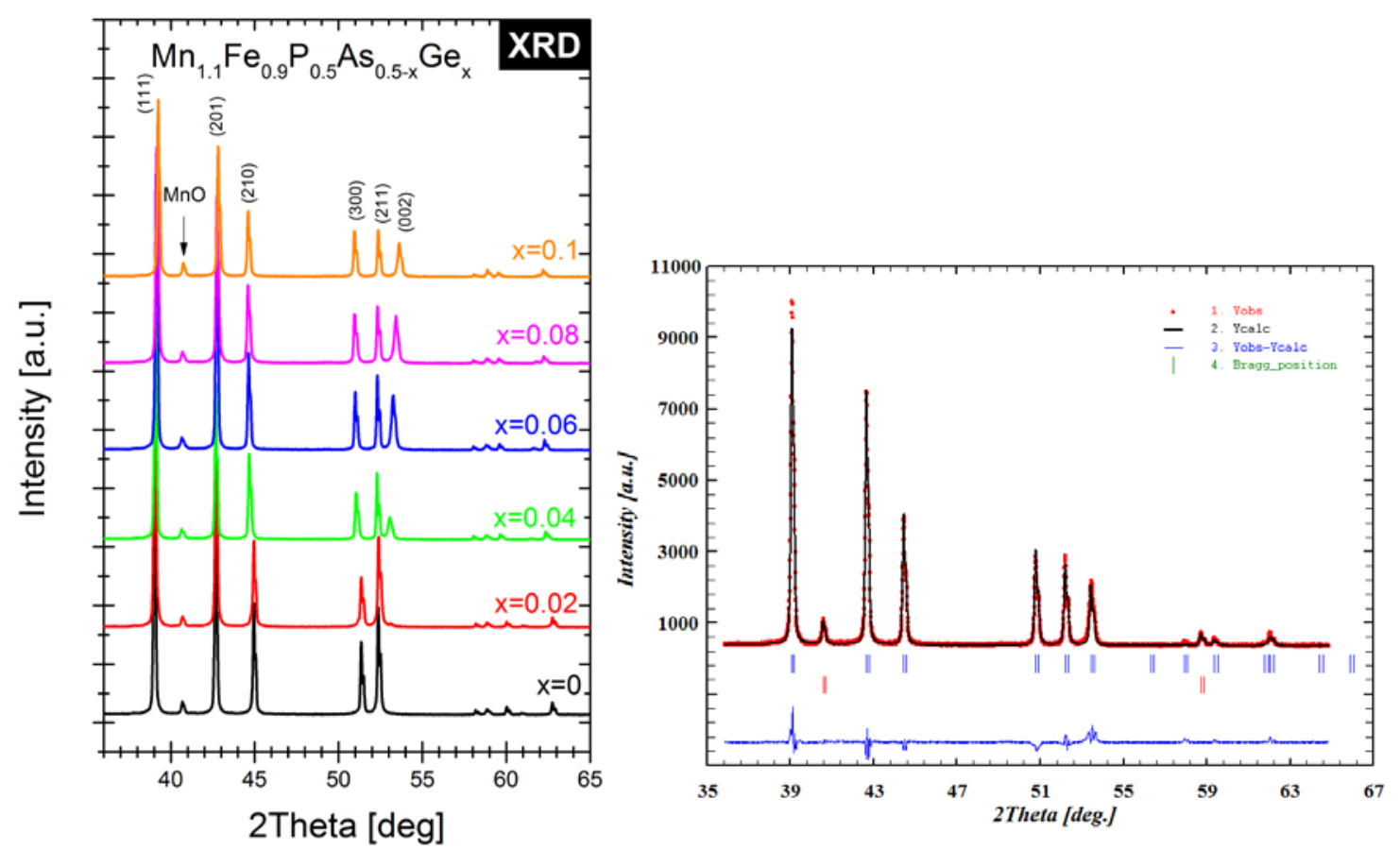

Figure 1. Diffraction patterns of all studied samples (left); Rietveld refinement plot for sample $\mathrm{Mn}_{1.1} \mathrm{Fe}_{0.9} \mathrm{P}_{0.5} \mathrm{As}_{0.4} \mathrm{Ge}_{0.1}$ (right). 
Table 1. The weight fractions of the refined phases, room temperature lattice parameters, calculated $c / a$ ratio and unit-cell volume for the $\mathrm{Fe}_{2} \mathrm{P}$-type phase.

\begin{tabular}{ccccccc}
\hline Ge Content: & Fe $_{2}$ P-type (\%) & MnO (\%) & $\mathbf{a}=\mathbf{b}(\mathbf{\AA})$ & $\mathbf{c}(\mathbf{\AA})$ & $\boldsymbol{c} / \boldsymbol{a}$ Ratio & $\mathbf{V}\left(\mathbf{\AA}^{3}\right)$ \\
\hline$x=0$ & $95.01 \pm 1.50$ & $4.99 \pm 0.29$ & $6.1716 \pm 0.0003$ & $3.4977 \pm 0.0001$ & 0.5667 & $115.377 \pm 0.008$ \\
$x=0.02$ & $95.29 \pm 0.70$ & $4.71 \pm 0.27$ & $6.1679 \pm 0.0002$ & $3.4932 \pm 0.0001$ & 0.5664 & $115.089 \pm 0.007$ \\
$x=0.04$ & $94.02 \pm 0.75$ & $5.98 \pm 0.35$ & $6.1972 \pm 0.0002$ & $3.4431 \pm 0.0001$ & 0.5572 & $114.852 \pm 0.007$ \\
$x=0.06$ & $94.13 \pm 1.30$ & $5.87 \pm 0.40$ & $6.2060 \pm 0.0004$ & $3.443 \pm 0.0002$ & 0.5547 & $114.840 \pm 0.012$ \\
$x=0.08$ & $94.97 \pm 1.23$ & $5.03 \pm 0.32$ & $6.2117 \pm 0.0003$ & $3.4337 \pm 0.0002$ & 0.5528 & $114.738 \pm 0.010$ \\
$x=0.1$ & $93.67 \pm 0.53$ & $6.33 \pm 0.38$ & $6.2232 \pm 0.0004$ & $3.4273 \pm 0.0002$ & 0.5507 & $114.949 \pm 0.012$ \\
\hline
\end{tabular}

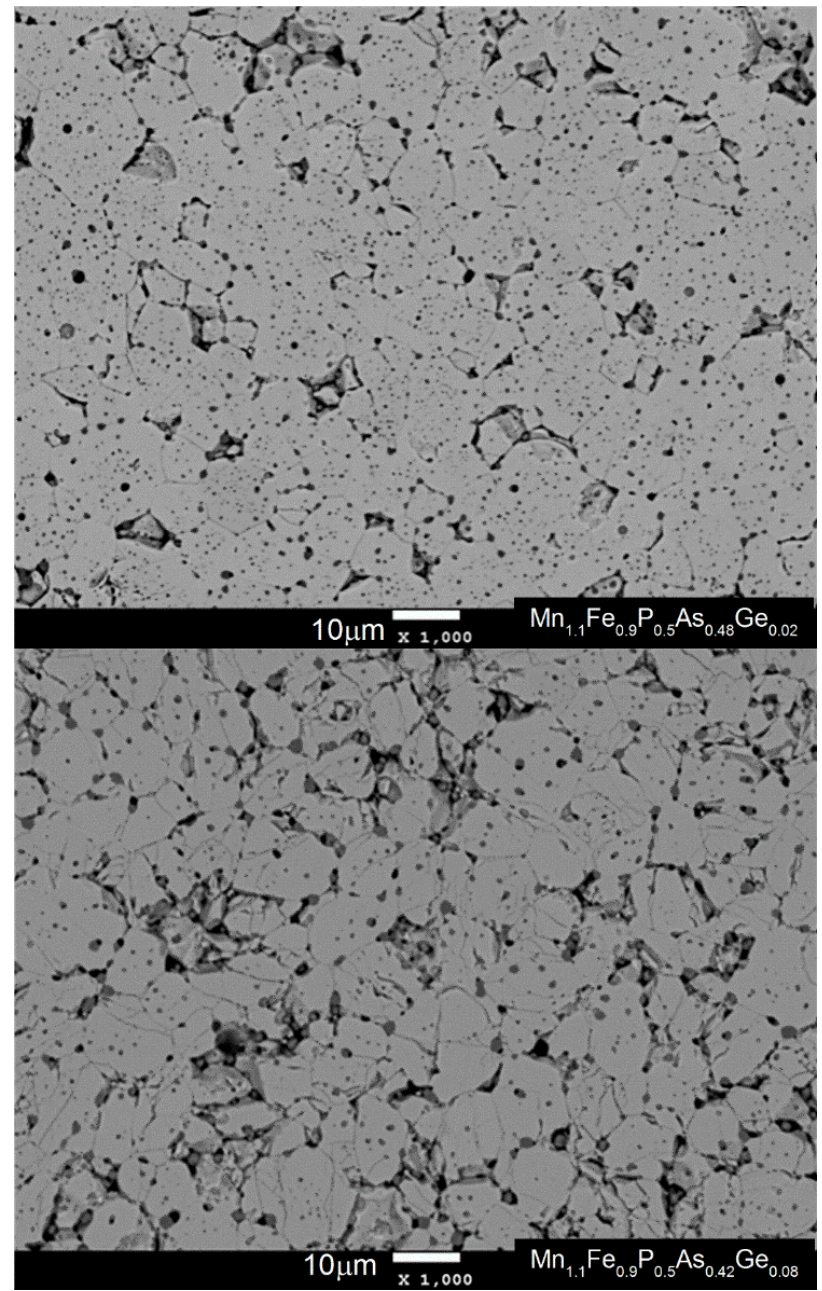

Figure 2. Microstructure of two different samples with germanium amounts of $x=0.02$ and $x=0.08$. At the measurement temperature, sample $x=0.02$ is paramagnetic while $x=0.08$ ferromagnetic.

Nominal and measured compositions of two samples $(x=0.02, x=0.08)$ are shown in Table 2 .

Table 2. Comparison of nominal and measured compositions of two whole samples (main phase + $\mathrm{MnO}$ impurity) and major magnetocaloric phase.

\begin{tabular}{ccc}
\hline & Sample 1 $\boldsymbol{x}=\mathbf{0 . 0 2}$ & Sample 2 $\boldsymbol{x}=\mathbf{0 . 0 8}$ \\
\hline Nominal composition & $\mathrm{Mn}_{1.10} \mathrm{Fe}_{0.90} \mathrm{P}_{0.50} \mathrm{As}_{0.48} \mathrm{Ge}_{0.02}$ & $\mathrm{Mn}_{1.10} \mathrm{Fe}_{0.90} \mathrm{P}_{0.50} \mathrm{As}_{0.42} \mathrm{Ge}_{0.08}$ \\
WDS average & $\mathrm{Mn}_{1.12} \mathrm{Fe}_{0.91} \mathrm{P}_{0.47} \mathrm{As}_{0.48} \mathrm{Ge}_{0.02} \mathrm{O}_{0.13}$ & $\mathrm{Mn}_{1.13} \mathrm{Fe}_{0.90} \mathrm{P}_{0.49} \mathrm{As}_{0.41} \mathrm{Ge}_{0.07} \mathrm{O}_{0.17}$ \\
WDS main phase & $\mathrm{Mn}_{1.07} \mathrm{Fe}_{0.92} \mathrm{P}_{0.48} \mathrm{As}_{0.49} \mathrm{Ge}_{0.02}$ & $\mathrm{Mn}_{1.06} \mathrm{Fe}_{0.95} \mathrm{P}_{0.49} \mathrm{As}_{0.42} \mathrm{Ge}_{0.08}$ \\
EDS average & $\mathrm{Mn}_{1.12} \mathrm{Fe}_{0.91} \mathrm{P}_{0.47} \mathrm{As}_{0.48} \mathrm{Ge}_{0.02} \mathrm{O}_{0.23}$ & $\mathrm{Mn}_{1.14} \mathrm{Fe}_{0.93} \mathrm{P}_{0.48} \mathrm{As}_{0.38} \mathrm{Ge}_{0.06} \mathrm{O}_{0.19}$ \\
\hline
\end{tabular}


The nominal composition stays in good agreement with the measured one. All of the samples have a disturbed $\mathrm{Mn} / \mathrm{Fe}$ ratio because of $\mathrm{MnO}$ second phase formation. From the WDS measurement of the chemical compositions, the amount of $\mathrm{MnO}$ was examined. It is equal to 4 at $\%$ in the case of the sample with $x=0.02$ and 5 at $\%$ in the case of the second sample $(x=0.08)$.

A series of studied compounds exhibit magnetoelastic first-order transition. DSC was used to evaluate latent heat of transition in the absence of a magnetic field. In Figure 3, one can see the thermograms for all of studied samples up to a germanium amount of $x=0.1$. The latent heat changes in the range of 3.1-4.6 J/g, and is lowest for the sample with $x=0.06$. In the range of compositions from $x=0.04$ to $x=0.10$, the minimum transition enthalpy is can be easily noted at $x=0.06$. It was also found that slight amount of germanium $(x=0.02)$ caused a decrease of latent heat from $4.0 \mathrm{to} 3.4 \mathrm{~J} / \mathrm{g}$. The temperature of transition depends linearly on the germanium amount in the sample. It varies from $276 \mathrm{~K}$ for the pure sample to $336 \mathrm{~K}$ for the germanium-doped sample with $x=0.10$. It can be also be predicted from the linear fit that the transformation at room temperature occurs for the composition with $x=0.035$.
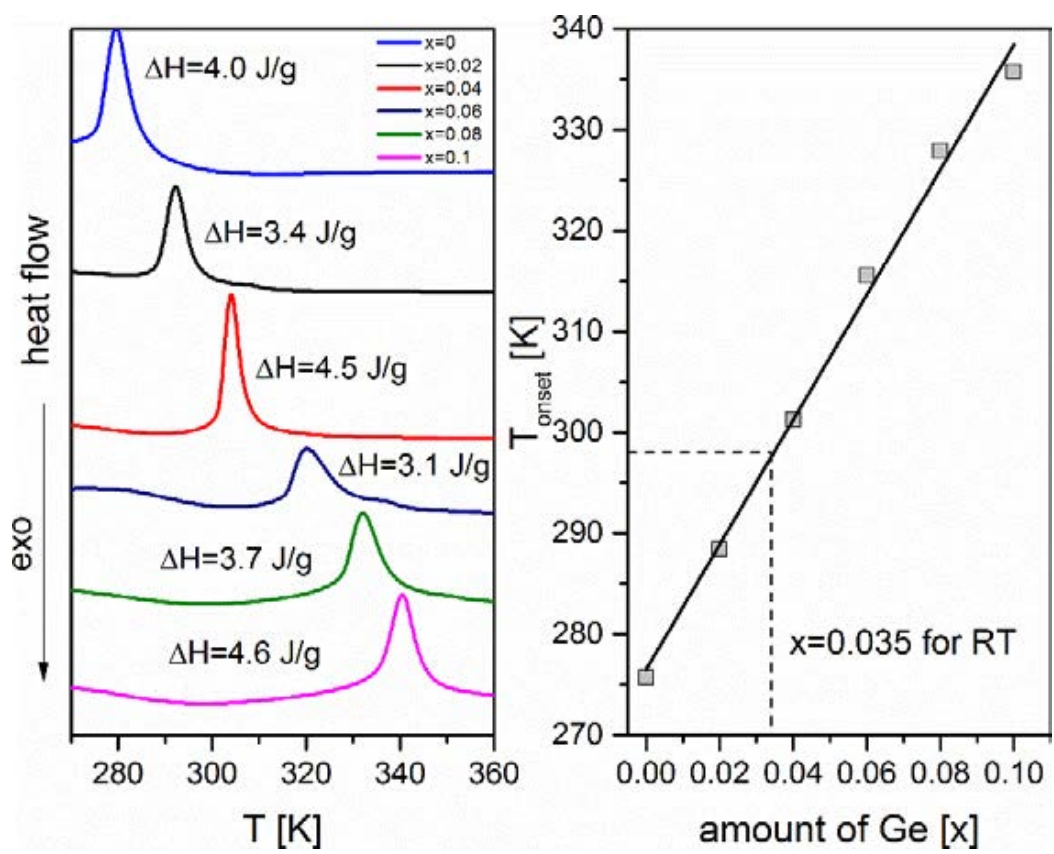

Figure 3. Results of DSC measurements. In the left panel, heating curves $(10 \mathrm{~K} / \mathrm{min})$ for all studied compounds are presented. Structural transition enthalpy was evaluated. In the right panel, onset temperatures of structural transition versus reciprocal temperature are plotted. From the linear fit, the transition at RT was found for composition $x=0.035$.

Magnetic entropy change was calculated for all of the studied samples for magnetic field change up to $B=1 \mathrm{~T}$. As one can see in Figure 4, the magnetic entropy change (at B=1 T) drops significantly with increasing concentration of germanium from $x=0.04$ to $x=0.06$, where it achieves a minimal value $\left(-\Delta \mathrm{S}_{\mathrm{M}}=5.5 \mathrm{~J} \cdot \mathrm{kg}^{-1} \cdot \mathrm{K}^{-1}\right)$.

The highest magnetic entropy change was obtained for a sample with the germanium amount of $x=0.02\left(-\Delta S_{M}=11.0 \mathrm{~J} \cdot \mathrm{kg}^{-1} \cdot \mathrm{K}^{-1}\right)$. Adiabatic temperature change (see Figure 5 for details) behaves the same way as the magnetic entropy change. It was found that by the slight substitution of germanium for arsenic $(x=0.02)$, the adiabatic temperature change raised from 1.75 to $2.75 \mathrm{~K}$ at $\mathrm{B}=1.7 \mathrm{~T}$. This quantity exhibits similarly as the magnetic entropy change minimum at the germanium amount of $x=0.04$. For this composition, the adiabatic temperature change equals $1.7 \mathrm{~K}$. It can be easily noticed that germanium substitution for arsenic leads to an increase of the Curie point. The sample exhibiting 
the highest magnetocaloric effect $(x=0.02)$ exhibits FM-PM transition at room temperature, which is advantageous from a practical point view.

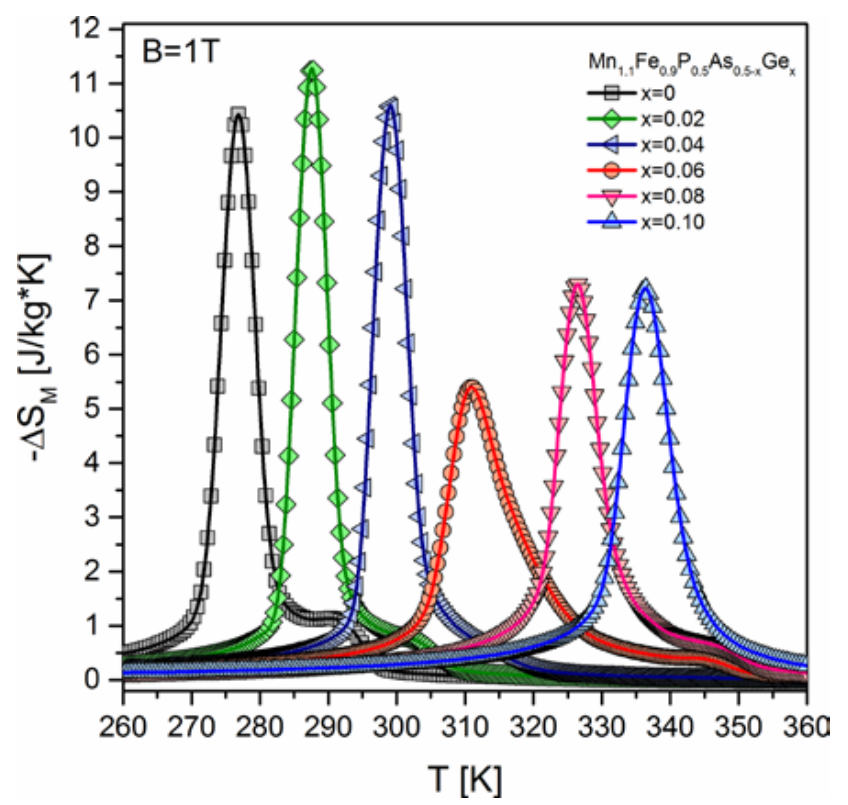

Figure 4. Magnetic entropy change calculated for all of the studied samples for magnetic field induction $\mathrm{B}=1 \mathrm{~T}$.

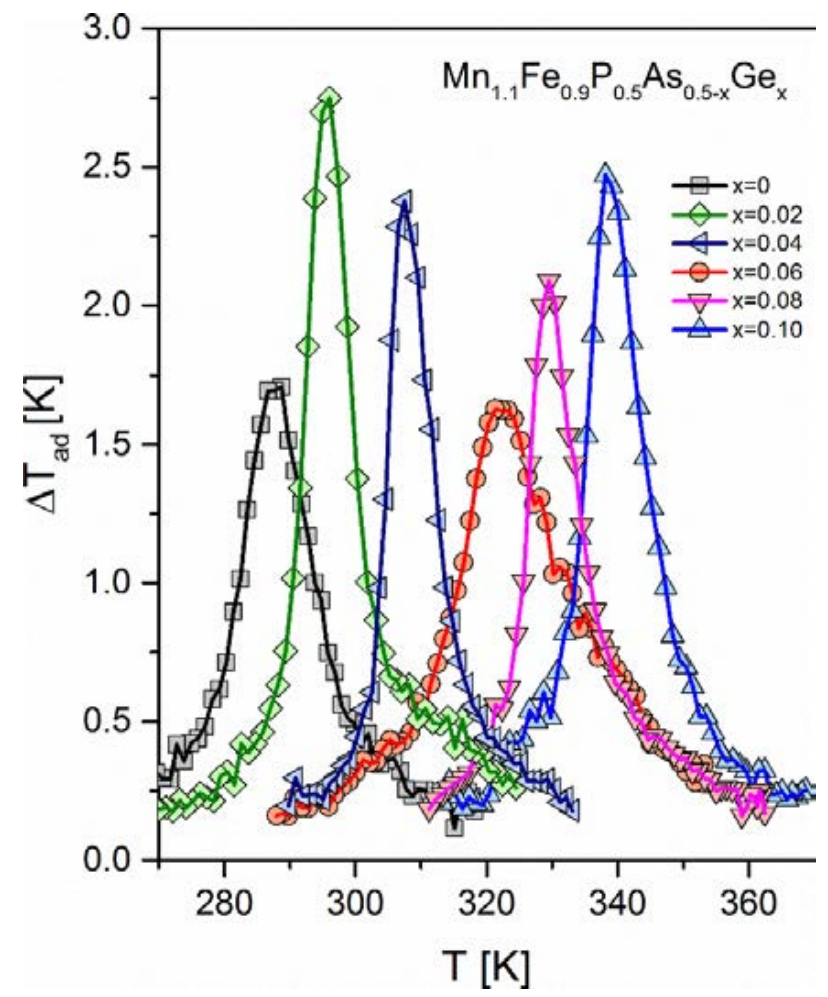

Figure 5. Adiabatic temperature change of all of the studied samples measured in a cooling regime under a magnetic field of $\mathrm{B}=1.7 \mathrm{~T}$.

Generally, the magnetocaloric effect is related to both the magnetic entropy change and latent heat of transition. In the MnFePAsGe series, the adiabatic temperature change has a similar germanium 
content dependence as the magnetic entropy change. Therefore, it can be assumed that magnetocaloric effect is mainly altered due to the change of the overall magnetic moment of the unit cell. Many studies, up to now, have indicated that the highest magnetic moment is localized mainly on manganese atoms $(\sim 2.9 \mu \mathrm{B})$ which prefer the $3 g$ Wyckoff position of the hexagonal $\mathrm{P}-62 \mathrm{~m}$ lattice cell. On the other hand, iron atoms prefer the $3 f$ positions (magnetic moment approximately $1.3 \mu \mathrm{B}$ ) and, in consequence, both elements form alternating planes (layers) in the crystal. Therefore, it can be predicted that mainly the modification of $3 g-3 g$ intralayer distances leads to large fluctuations of the cell's magnetic moment and consequently to the alteration of magnetocaloric effect. Despite the fact that germanium atoms have a higher atomic radius than arsenic ( $125 \mathrm{pm}$ for Ge versus $115 \mathrm{pm}$ for As), a substitution of germanium for arsenic up to the value of $x=0.08$ leads to the unit cell volume contraction. Moreover, the ratio of lattice constants $c / a$ decreases with the increasing amount of germanium in the whole range of studied germanium concentrations. Both parameters have been refined from the X-ray diffraction data, and are gathered in Figure 6. Such modifications of structure leads to the change of magnetic atoms ( $\mathrm{Fe}$ and $\mathrm{Mn}$ ) distances in and between layers. It was found that the composition-dependent magnetocaloric parameters can be correlated with the changing $3 g-3 g$ intralayer distances. In Figure 7 , $3 g-3 g$ and $3 f-3 f$ distances are plotted as a function of germanium content. As one can see, the $3 g-3 g$ distance exhibits the same minimum as was found for adiabatic temperature and magnetic entropy change. Contrary to the behavior of the $3 g$ - $3 g$ distance, the $3 f-3 f$ intralayer distance rises in the whole range of germanium concentrations. Assuming that Mn atoms are placed in the $3 g$ Wyckoff positons, by substituting a non-magnetic metalloid atom, i.e., arsenic or phosphorous, for atoms with different atomic radius, one can control the Mn-Mn atomic distance in a crystalline cell, which affects magnetocaloric effect. The sample with composition $\mathrm{Mn}_{1.1} \mathrm{Fe}_{0.9} \mathrm{P}_{0.5} \mathrm{As}_{0.48} \mathrm{Ge}_{0.02}$ has certain parameters, i.e., a magnetic entropy change calculated for magnetic field induction of $\mathrm{B}=1 \mathrm{~T}$ and the Curie temperature, similar to the sample obtained by Tegus et al. with composition $\mathrm{Mn}_{1.1} \mathrm{Fe}_{0.9} \mathrm{P}_{0.7} \mathrm{As}_{0.2} \mathrm{Ge}_{0.1}$.

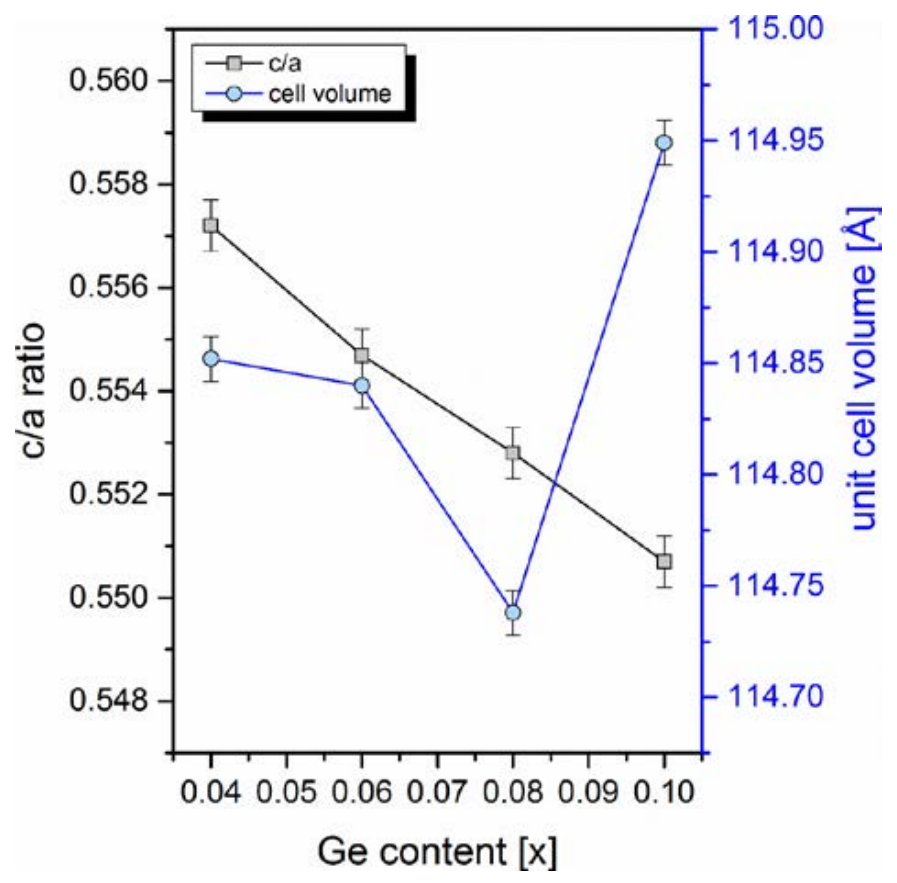

Figure 6. Unit cell volume and lattice parameters ratio $(c / a)$ as a function of germanium content, derived from XRD measurements (for ferromagnetic samples at $\mathrm{T}=298 \mathrm{~K}$ ). Lines are guides for the eyes. 


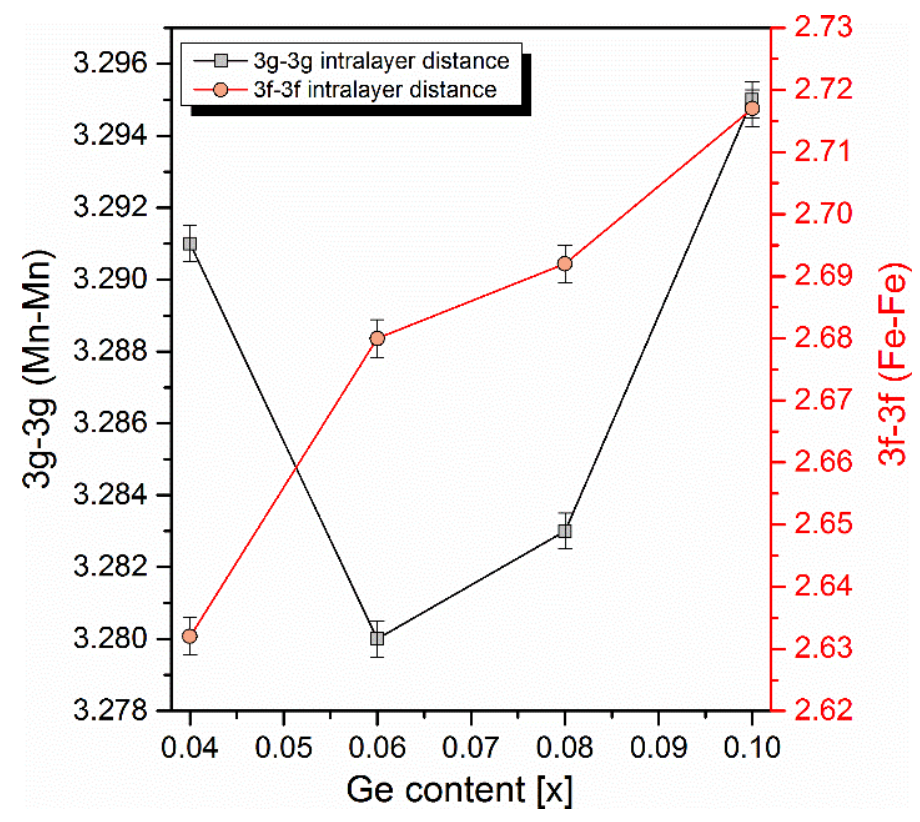

Figure 7. Intralayer $3 g-3 g$ and $3 f-3 f$ atom distances as a function of germanium content (data presented for ferromagnetic samples at $\mathrm{T}=298 \mathrm{~K})$. Lines are guides for the eyes.

\section{Summary}

It was found that the substitution of the non-magnetic site in $(\mathrm{Mn}, \mathrm{Fe})_{2}(\mathrm{P}, \mathrm{As})$ quaternary compounds by the fifth element may lead to greatly enhanced magnetocaloric properties induced by the alteration of distances of magnetic elements $(\mathrm{Mn}, \mathrm{Fe})$. Germanium-doped quinary $\mathrm{Mn}_{1.1} \mathrm{Fe}_{0.9} \mathrm{P}_{0.5} \mathrm{As}_{0.5-x} \mathrm{Ge}_{x}$ compounds were obtained as an almost pure magnetocaloric phase with a small amount of $\mathrm{MnO}$ impurity. Germanium doping at $x=0.02$ raised the adiabatic temperature change from 1.75 to $2.75 \mathrm{~K}$ at $\mathrm{B}=1.7 \mathrm{~T}$, i.e., by $40 \%$, while the magnetic entropy change at $\mathrm{B}=1 \mathrm{~T}$ was raised by $10 \%$ (from -10.5 to $-11.5 \mathrm{~J} \cdot \mathrm{kg}^{-1} \cdot \mathrm{K}^{-1}$ ). For the germanium fraction $x=0.06$, the magnetocaloric effect is at the minimum $\left(\Delta \mathrm{T}=1.6 \mathrm{~K}, \Delta \mathrm{S}=-5.5 \mathrm{~J} \cdot \mathrm{kg}^{-1} \cdot \mathrm{K}^{-1}\right)$, which corresponds to the minimal value of the $3 g-3 g$ intralayer distance (position of manganese atoms).

Acknowledgments: L. Hawelek is acknowledged for a grant from the National Science Center, Poland (2011/01/D/ST5/07816). A. Kolano-Burian, P. Wlodarczyk, M. Kowalczyk and M. Polak are acknowledged for a grant from NCBR, Poland (grant No. PBS2/A5/36/2013).

Author Contributions: P. Wlodarczyk and L. Hawelek conceived and designed the experiments; M. Kowalczyk performed magnetic measurements; M. Kaminska performed WDS/EDS measurements and analyzed data; L. Hawelek and M. Polak performed X-Ray measurements and analyzed data; P. Wlodarczyk and A. Kolano-Burian performed DSC measurements and analyzed data. P. Wlodarczyk and A. Hudecki performed $\Delta \mathrm{T}$ measurements and analyzed data; P. Wlodarczyk wrote the paper.

Conflicts of Interest: The authors declare no conflict of interest. The founding sponsors had no role in the design of the study; in the collection, analyses, or interpretation of data; in the writing of the manuscript, and in the decision to publish the results.

\section{References}

1. Lyubina, J.; Gutfleisch, O.; Kuzmin, M.D.; Richter, M. La(Fe,Si) ${ }_{13}$-based magnetic refrigerants obtained by novel processing routes. J. Magn. Magn. Mater. 2009, 321, 3571-3577. [CrossRef]

2. Phejar, M.; Paul-Boncour, V.; Bessais, L. Structural and magnetic properties of magnetocaloric $\mathrm{LaFe}_{13-x} \mathrm{Si}_{x}$ compounds synthesized by high energy ball-milling. Intermetallics 2010, 18, 2301-2307. [CrossRef]

3. Ilyn, M.; Tishin, A.M.; Hu, F.X.; Gao, J.; Sun, J.R.; Shen, B.G. Magnetocaloric properties of the LaFe $\mathrm{Le}_{11.7} \mathrm{Si}_{1.3}$ and $\mathrm{LaFe}_{11.2} \mathrm{Co}_{0.7} \mathrm{Si}_{1.1}$ systems. J. Magn. Magn. Mater. 2005, 290-291, 712-714. [CrossRef] 
4. Bez, H.N.; Eggert, B.G.F.; Lozano, J.A.; Bahl, C.R.H.; Barbosa, J.R., Jr.; Teixeira, C.S.; Wendhausen, P.A.P. Magnetocaloric effect and $\mathrm{H}$ gradient in bulk $\mathrm{La}(\mathrm{Fe}, \mathrm{Si})_{13} \mathrm{Hy}$ magnetic refrigerants obtained by $\mathrm{HDSH}$. J. Magn. Magn. Mat. 2015, 386, 125-128. [CrossRef]

5. Fujieda, S.; Hasegawa, Y.; Fujita, A.; Fukamichi, K. Direct measurement of magnetocaloric effects in itinerant-electron metamagnets $\mathrm{La}\left(\mathrm{Fe}_{x} \mathrm{Si}_{1-x}\right)_{13}$ compounds and their hydrides. J. Magn. Magn. Mater. 2004, 272-276, 2365-2366. [CrossRef]

6. Wlodarczyk, P.; Polak, M.; Hawelek, L.; Kowalczyk, M.; Hreczka, M.; Kolano-Burian, A. Chemical hydrogenation of $\mathrm{La}(\mathrm{Fe}, \mathrm{Si})_{13}$ family of intermetallic compounds. Solid State Sci. 2016, 61, 246-251. [CrossRef]

7. Tegus, O.; Bruck, E.; Li, X.W.; Zhang, L.; Dagula, W.; de Boer, F.R.; Buschow, K.H.J. Tuning of the magneto-caloric effects in MnFe(P,As) by substitution of elements. J. Magn. Magn. Mater. 2004, 272-276, 2389-2390. [CrossRef]

8. Bruck, E.; Ilyn, M.; Tishin, A.M.; Tegus, O. Magnetocaloric effects in $\mathrm{MnFeP}_{1-x} \mathrm{As}_{x}$-based compounds. J. Magn. Magn. Mater. 2005, 290-291, 8-13. [CrossRef]

9. Tegus, O.; Bruck, E.; Buschow, K.H.J.; de Boer, F.R. Transition-metal-based magnetic refrigerants for room-temperature applications. Nature 2002, 415, 150-152. [CrossRef] [PubMed]

10. Thanh, D.T.C.; Bruck, E.; Trung, N.T.; Klaasse, J.C.P.; Buschow, K.H.J.; Ou, Z.Q.; Tegus, O.; Caron, L. Structure, magnetism, and magnetocaloric properties of MnFeP1—xSix compounds. J. Appl. Phys. 2008, 103, $07 \mathrm{~B} 318$. [CrossRef]

11. Trung, N.T.; Ou, Z.Q.; Gortenmulder, T.J.; Tegus, O.; Buschow, K.H.J.; Bruck, E. Tunable thermal hysteresis in MnFe (P, Ge) compounds. Appl. Phys. Lett. 2009, 94, 102513. [CrossRef]

12. Dung, N.H.; Ou, Z.Q.; Caron, L.; Zhang, L.; Thanh, D.T.C.; de Wijs, G.A.; de Groot, R.A.; Buschow, K.H.J.; Bruck, E. Mixed magnetism for refrigeration and energy conversion. Adv. Energy Mater. 2011, 1, 1215-1219. [CrossRef]

13. Yibole, H.; Guillou, F.; Zhang, L.; van Dijk, N.H.; Bruck, E. Direct measurement of the magnetocaloric effect in $\mathrm{MnFe}(\mathrm{P}, \mathrm{X})(\mathrm{X}=\mathrm{As}, \mathrm{Ge}, \mathrm{Si})$ materials. J. Phys. D Appl. Phys. 2014, 47, 075002. [CrossRef]

14. Tegus, O.; Fuquan, B.; Dagula, W.; Zhang, L.; Bruck, E.; Si, P.Z.; de Boer, F.R.; Buschow, K.H.J. Magnetic-entropy change in $\mathrm{Mn}_{1.1} \mathrm{Fe}_{0.9} \mathrm{P}_{0.7} \mathrm{As}_{0.3-x} \mathrm{Ge}_{x}$. J. Alloys Compd. 2005, 396, 6-9. [CrossRef]

15. Wlodarczyk, P.; Hawelek, L.; Kowalczyk, M.; Kaminska, M.; Zackiewicz, P.; Polak, M.; Hreczka, M.; Kolano-Burian, A. Impact of silicon doping on the magnetocaloric effect of $\mathrm{MnFeP}_{0.35} \mathrm{As}_{0.65}$ powder. Solid State Sci. 2016, 56, 23-28. [CrossRef]

16. Rodríguez-Carvajal, J. Recent advances in magnetic structure determination by neutron powder diffraction. Phys. B Condens. Matter 1993, 192, 55-69. [CrossRef]

17. Caron, L.; Ou, Z.Q.; Nguyen, T.T.; Thanh, D.T.C.; Tegus, O.; Brück, E. On the determination of the magnetic entropy change in materials with first-order transitions. J. Magn. Magn. Mater. 2009, 321, 3559-3566. [CrossRef]

(C) 2017 by the authors. Licensee MDPI, Basel, Switzerland. This article is an open access article distributed under the terms and conditions of the Creative Commons Attribution (CC BY) license (http://creativecommons.org/licenses/by/4.0/). 